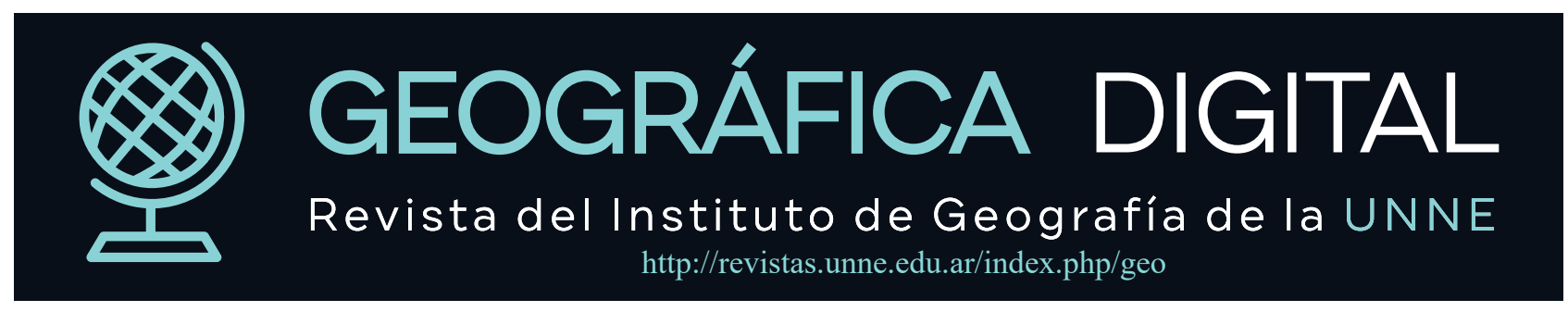

Revista Geográfica Digital, 2021, Vol. 18, N 36, 118-134 pp., E-ISSN: 1668-5180: DOI: http://dx.doi.org/10.30972/geo.18365619

\title{
Aplicación de un índice integrado de riesgo a la sequía meteorológica en la cuenca del Río mataquito, Región del Maule, Chile
}

\author{
Application of an integrated meteorological drought risk index in the \\ Mataquito River basin, Maule Region, Chile
}

\section{Carrasco, Claudia A .; Huaico, Ana I².}

1'Departamento de Geografía. Universidad de Concepción. ccarrasco2016@udec.cl

22Departamento de Geografía. .Universidad de Concepción. ahuaico@udec.cl

Palabras claves:

Índice del riesgo a la sequía meteorológica

Índice de amenaza

Índice de precipitación

estandarizada

Índice de vulnerabilidad

\section{R E S U M E N}

La presente investigación tiene como objetivo desarrollar un índice integrado de riesgo para evaluar sequía meteorológica en la cuenca del Río Mataquito, Región del Maule en Chile. Lo anterior se conceptualiza bajo la definición de riesgo, para lo cual fue necesario, estudiar la amenaza y la vulnerabilidad. Para ello se seleccionaron variables, indicadores e índices con el fin de evaluar el fenómeno de la sequía meteorológica de forma integral, de una manera simple y a partir de datos de libre acceso, a fin de obtener una metodología que fuera replicable. De esta forma se utiliza el índice de precipitación estandarizada (SPI) para el diagnóstico de la amenaza a la sequía meteorológica y los indicadores de vulnerabilidad se enfocan en la actividad agrícola en el medio rural, en función de los factores de exposición, sensibilidad y capacidad de adaptación. Como resultado se obtienen diferentes categorías de susceptibilidad al riesgo, en donde la categoría de riesgo extremo se localiza en los distritos costeros y en la depresión central. Se concluye que este ejercicio es útil para la planificación y monitoreo de la sequía en la cuenca del Río Mataquito, pero también es un ejercicio replicable a otras cuencas agrícolas.

\section{A B S T R A C T}

Keywords:

Meteorological drought risk index Hazard index

Standardized precipitation index Vulnerability index
The objective of this research is to develop an integrated index of meteorological drought risk in the Mataquito River basin, Maule Region, Chile. This is conceptualized under the definition of risk, for which it was necessary to study the threat and vulnerability. For this purpose, variables, indicators and indexes were selected in order to evaluate the meteorological drought phenomenon in an integral manner, in a simple way and from freely available data, so as to obtain a methodology that could be replicated. In this way, the standardized precipitation index (SPI) is used to diagnose the hazard of meteorological drought and the vulnerability indicators are focused on agricultural activity in rural areas, based on the factors of exposure, sensitivity and adaptive capacity. As a result, different risk susceptibility categories are obtained, where the extreme risk category is located in coastal districts and in the central depression. It is concluded that this exercise is useful for drought planning and monitoring in the Mataquito River basin, but it is also an exercise that can be reproduced in other agricultural basins. 


\section{Introducción}

Chile es uno de los países más vulnerables al cambio climático global, se estima una intensificación de la aridez en la zona norte, avance del desierto hacia el sur y reducción hídrica en la zona central (Organización de las Naciones Unidas para la Alimentación y la Agricultura [FAO], 2010). Esta última ha presentado actualmente una de las mayores preocupaciones de la sociedad, debido a diversos eventos que se han manifestado en el territorio.

La reducción hídrica se produce por una alteración en el ciclo hidrológico, proceso natural que sumada a la presión que ejerce en el recurso la actividad humana se conjugan de manera negativa dando como resultado déficits de agua, que se manifiesta en forma de sequía y/o escasez hídrica. El primer fenómeno, obedece a una falta temporal de agua comparada con condiciones normales provocada por anomalías meteorológicas (Van Loon et al., 2016). A su vez, la escasez hídrica se define como el "desequilibrio entre el suministro y la demanda de agua dulce en un área determinada (...) como resultado de una demanda demasiado elevada para el suministro disponible, bajo las condiciones existentes de disposiciones institucionales (...) y de infraestructuras" (FAO,2013, p.71).

Desde el año 2010 el país se está viendo afectado por el fenómeno de megasequía, caracterizado por una secuencia ininterrumpida de años secos con un déficit medio de precipitaciones de 20 a $40 \%$ en la década más cálida de los últimos 100 años, abarcando a gran parte del país (Centro de Ciencia del Clima y la Resiliencia [CR ${ }^{2}$ ], 2015). Sin precedentes en los registros locales, contribuye a una tendencia seca de larga data en la región, presenta efectos perjudiciales sobre la disponibilidad de agua, la vegetación y los incendios forestales, aumenta el déficit hídrico a través de la evaporación desde lagos, embalses y cultivos limitando principalmente la producción agrícola (Garreaud et al., 2019).

El riesgo de sequía se considera como la amenaza que provoca el descenso de la oferta de agua disponible, causa impactos tanto sociales, económicos y/o ambientales que varían según la vulnerabilidad del territorio, y que en situaciones críticas pueden desencadenar un desastre o catástrofe $\left(\mathrm{CR}^{2}, 2015\right)$.

En esta investigación se enfatiza el papel combinado de la amenaza y la vulnerabilidad en la evaluación del riesgo, por lo cual, se elaboró y aplicó un índice integrado de riesgo a la sequía meteorológica conformado por el índice de amenaza de sequía meteorológica y el índice de vulnerabilidad a la sequía. Estos índices representan la amenaza como la disminución de precipitación entorno a la media y la vulnerabilidad de la población compuesta por los indicadores, exposición, sensibilidad y adaptabilidad, con énfasis en las zonas rurales y en la producción agrícola en particular de la cuenca del Río Mataquito, Región del Maule. Bajo la hipótesis de que aquellos sectores rurales con gran desarrollo de la actividad agrícola en el valle central de la cuenca presentan mayores niveles al riesgo de sequía meteorológica, ya que son áreas más vulnerables.

\section{Marco teórico}

\subsection{Clasificaciones conceptuales, la sequía, sequía meteorológica y su evaluación}

La sequía es definida como un fenómeno extremo que consiste en la nula precipitación o en su reducción por debajo del promedio durante un periodo de tiempo (Castillo-Castillo et al., 2017). Corresponde más bien a una definición expresada en términos relativos que no considera umbrales de referencia ni las condiciones climáticas del lugar, por ello es que en la práctica se utiliza una definición operacional, la cual requiere de la identificación del momento de inicio, finalización e intensidad, como también la consideración de diversidad de climas ante lo cual se recomienda definir el umbral específicamente por región y actividad, atendiendo a las características propias del fenómeno (Hayes et al., 2004; Valiente, 2001).

Existen cuatro grandes categorías de sequía relacionadas entre sí; sequía meteorológica, sequía hidrológica, sequía agrícola y sequía socioeconómica. La secuencia de ocurrencia de sequía comienza con la sequía meteorológica causada por la deficiencia de precipitación, seguida por la sequía hidrológica, que puede afectar los caudales de los ríos, los niveles en los lagos y la recarga de los acuíferos, una prolongación de esta puede causar una sequía agrícola a medida que el déficit de precipitación se propaga al déficit de humedad del suelo y reduce la producción de cultivos. Un período extenso de esto último causará impactos socioeconómicos, catalogados como sequía socioeconómica la cual puede desencadenar en hambrunas y migración ambiental con grandes masas de refugiados (Nasrollahi et al., 2018; Valiente, 2001; Wilhite \& Glantz, 1985). 
La sequía meteorológica se define como la falta de precipitación en una región durante un periodo de tiempo (Valiente, 2001). Se basa netamente en los datos climáticos referidos al déficit de precipitación. Generalmente se considera cuando la deficiencia de lluvia estacional excede el 25\% de su promedio a largo plazo (CWC,1996; como se citó en Rahman \& Lateh, 2016).

El índice de precipitación estandarizado SPI por sus siglas en inglés (Standardized Precipitation Index) propuesto por Mckee et al. (1993), es recomendado por la Organización Meteorológica Mundial para la estimación de la sequía del tipo meteorológica, dado que su única variable es la precipitación en un periodo determinado que sea entre un mínimo de 20 a 30 años (Organización Meteorológica Mundial [OMM], 2012; Nasrollahi et al., 2018; Sharafi et al., 2020). Indica la magnitud estadística de la desviación del promedio de precipitación, de modo que permite la identificación de una condición de sequía en una escala de tiempo determinada (McKee et al., 1993; Rahman \& Lateh, 2016). El valor del índice se puede obtener mediante cálculos estadísticos manuales y/o mediante el uso de software especializados.

\subsection{Conceptualización del Riesgo, Amenaza y Vulnerabilidad}

Se entiende por riesgo natural como "la probabilidad de que en un espacio ocurra un peligro determinado de origen natural, y que pueda generar potenciales daños y pérdidas en las actividades humanas" (Rojas \& Martínez, 2011, p.86). El riesgo puede reducirse si se entiende como el resultado de relacionar la amenaza o probabilidad de ocurrencia de un evento, y la vulnerabilidad de los elementos expuestos (Cardona, 1993). Estos componentes se encuentran intrínsecamente relacionados, puesto que no se puede ser vulnerable si no se está amenazado y que no existe una condición de amenaza para un elemento, sujeto o sistema si no está expuesto y es vulnerable a la acción potencial que representa dicha amenaza.

El análisis de riesgo para esta investigación se refiere al proceso de identificación y comprensión de los componentes relevantes del riesgo de sequía. Por lo tanto, el riesgo de sequía se entiende como el impacto potencial de las sequías en el medio ambiente, el desarrollo social y el bienestar humano, que es el resultado de interacciones complejas entre la amenaza y la vulnerabilidad al fenómeno (Intergovernmental Panel on Climate Change [IPCC], 2014).

La definición de amenaza o peligro es "la probabilidad de ocurrencia de un evento potencialmente desastroso durante cierto período de tiempo en un sitio dado" (Organización de las Naciones Unidas para la Ayuda en Casos de Desastre [UNDRO], 1979, p.5). Se identifica la existencia de un peligro latente asociado con un fenómeno físico de origen natural o antrópico que puede presentarse en un sitio específico y en un tiempo determinado capaz de causar pérdidas de gravedad, la valoración del desastre es dada por las personas afectadas. Aneas de Castro (2000) identifica que el "Peligro implica la existencia del hombre que valora qué es un daño y qué no". (p.10)

Por vulnerabilidad se entiende como "la propensión o predisposición a verse afectado negativamente" (IPCC, 2012, p.32). Surge de la interacción de diferentes factores y características que determina el grado de susceptibilidad de las personas, comunidades o regiones ante un peligro, dado que está estrechamente relacionada a factores económicos, sociales, geográficos, demográficos, culturales, institucionales, de gobierno y ambientales, puede variar según el nivel de la exposición variable al peligro o las habilidades que presente la población para afrontarlo (Hayes et al., 2004).

Diversos autores identifican que la vulnerabilidad es una función de tres factores, exposición, sensibilidad y capacidad de adaptación (IPCC, 2007; Sharafi et al., 2020).

La Exposición considera la presencia de personas, medios de subsistencia, servicios y recursos ambientales, infraestructura, o activos económicos, sociales o culturales, en lugares que podrían verse afectados por estar en el área de influencia de los fenómenos peligrosos y por su fragilidad física ante los mismos (Cardona, 2001).

La Sensibilidad define aquellas condiciones del sistema que hacen que sea más probable que sufra daños como resultado de un desastre natural (IPCC, 2007). Cardona (2001), lo identifica como fragilidad social, ya que corresponde a la predisposición de la población ante el peligro, como resultado de la marginalidad y segregación social de un asentamiento humano.

La adaptabilidad o capacidad de adaptación son aquellas características y capacidades que permiten a una sociedad afrontar un fenómeno, ya sea en el momento que ocurre, o como parte de un proceso continuo de aprendizaje, experimentación y cambio en relación con la forma en que se enfrentan a través de la preparación, prevención y mitigación (Vargas \& Paneque, 2017). En cuanto a lo relacionado con la actividad agrícola, este indicador permite determinar las capacidades de adaptación y generación 
de producción de acuerdo con los niveles diferenciales de adopción de innovaciones tecnológicas dentro de la actividad (FAO, 2010).

\section{3. Área de estudio}

La cuenca del río Mataquito (Figura 1) se ubica entre los $34^{\circ} 50^{\prime}$ y $35^{\circ} 50^{\prime}$ de latitud sur, al norte de la Región del Maule. Posee una superficie de $6.190 \mathrm{~km}^{2}$ equivalentes al $20 \%$ de la superficie de la región. Se compone por los sistemas hidrológicos de los ríos Teno, Lontué y Mataquito, y los esteros río Seco y Carretón. Bajo la influencia del clima mediterráneo con al menos dos meses consecutivos del verano con déficit hídrico. La temperatura media anual es de $19^{\circ} \mathrm{C}$, con una máxima de $30^{\circ} \mathrm{C}$ y mínima de $7^{\circ} \mathrm{C}$ con una precipitación promedio anual de 740 mm (Dirección General de Aguas [DGA], 2004).

La selección de la cuenca como unidad territorial se justifica en que representa una unidad funcional propicia para el manejo y gestión del territorio, en especial por su funcionamiento unitario que permite realizar una gestión hídrica focalizada en el ciclo del agua (Gómez Orea, 2013). En vista de que la cuenca representa un límite natural y no administrativo, para el desarrollo de la investigación se utilizaron las divisiones censales distritales de las comunas que abarca la cuenca. Estas fueron homogeneizada y ajustadas a la cuenca del río Mataquito, identificando un total de 64 distritos censales.

Figura 1. Área de estudio, donde del 1 al 64 corresponden a distritos censales.

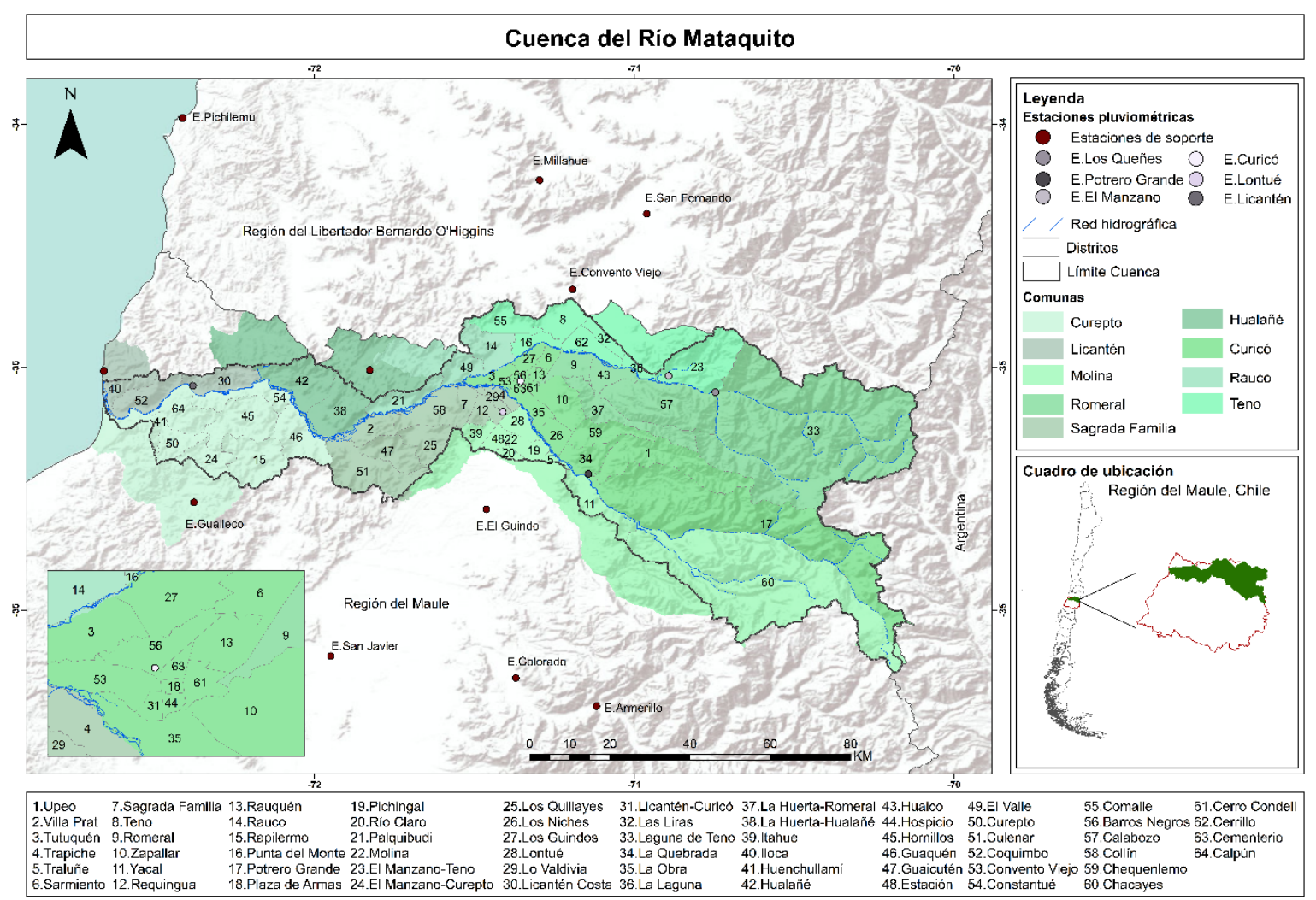

Fuente: elaboración propia.

\section{Materiales y métodos}

\subsection{Análisis del riesgo a la sequía}

La identificación y mapeo del riesgo a la sequía meteorológica se realizó mediante el índice de riesgo de sequía (DRI-drought risk index) en función del índice de amenaza de sequía (DHI-drought Hazard index) y el índice de vulnerabilidad de sequía (DVI-drought vulnerability index) (Nasrollahi et al., 2018; Rahman \& Lateh, 2016; Vargas \& Paneque, 2017). Lo cual queda expresado como: 


\section{$D R I=D H I \times D V I$}

Ecuación 1. DRI-drought risk index

La amenaza se determinó mediante el índice de precipitación estandarizada-SPI, mientras que la vulnerabilidad se calculó por medio de los factores de exposición, sensibilidad y adaptabilidad. En tanto, el resultado del índice de riesgo a la sequía meteorológica se materializa en la construcción del mapa de riesgo a la sequía meteorológica clasificado en cuatros niveles de riesgo; bajo, moderado, severo y extremo.

\subsection{Aplicación del Índice de Amenaza de Sequía Meteorológica}

Para el cálculo del índice de precipitación estandarizada-SPI se utilizó el software DrinC, con un periodo de tiempo de 41 años (1979-2019) y un ajuste del SPI a escala de 12 meses (Tigkas et al., 2015). La salida de los valores de estimación de sequía del programa DrinC en formato Excel son la entrada al Sistema de Información Geográfica (SIG) en el cual se realizó la categorización del índice de amenaza de sequía meteorológica según el promedio anual de cada estación y su categoría de sequía correspondiente para finalizar en la espacialización de la amenaza a través de la cartografía utilizando el método de interpolación estocástica kriging del software ArcGIS (Nasrollahi et al., 2018; OMM,2012).

El cálculo del SPI se basa en el registro de precipitación a largo plazo del período deseado, la cual se ajusta a una distribución de probabilidades Gamma que permite calcular la distribución de probabilidad acumulativa para una estación específica en una escala de tiempo definida, pero dado que la precipitación puede contener ceros, la probabilidad acumulativa se debe ajustar según la probabilidad de que no llueva, para ello se transforma a una distribución normal de media cero y una varianza de uno (Nasrollahi et al., 2018; OMM,2012). La función obtenida indica la probabilidad acumulada de un evento de lluvia para una estación, permitiendo establecer valores de clasificación para el SPI y realizar una estimación de los períodos secos y los períodos de humedad. Los distintos valores SPI definen los diferentes niveles de déficit o superávit de precipitación, las cuales son clasificadas por McKee et al. (1993, como se citó en OMM,2012) Tabla 1:

Tabla 1. Valores del índice normalizado de precipitación.

\begin{tabular}{|c|l|}
\hline Valor SPI & \multicolumn{1}{|c|}{ Clasificación } \\
\hline 2,0 y más & Extremadamente húmedo \\
\hline 1,5 a 1,99 & Muy húmedo \\
\hline 1,0 a 1,49 & Moderadamente húmedo \\
\hline$-0,99$ a 0,99 & Normal o aproximadamente normal \\
\hline$-1,0$ a $-1,49$ & Moderadamente seco \\
\hline$-1,5$ a $-1,99$ & Severamente seco \\
\hline-2 y menos & Extremadamente seco \\
\hline
\end{tabular}

Fuente: OMM (2012).

Los valores negativos de SPI indican una precipitación menor que la media los cuales se asocian a períodos de sequía, considerando que los episodios de sequía tienen lugar siempre y cuando el SPI alcance una intensidad de -1,0 o inferior y finaliza cuando el SPI se vuelve positivo (Nasrollahi et al., 2018; OMM, 2012). La categorización de la sequía permite definir el nivel de amenaza. En esta investigación, se utilizaron las siguientes categorías de sequía para definir el nivel de amenaza (Tabla 2), con base en lo propuesto por Nasrollahi et al. (2018).

Tabla 2. Categoría de sequía y nivel de amenaza.

\begin{tabular}{|c|l|c|}
\hline Valor SPI & \multicolumn{1}{|c|}{ Clasificación } & $\begin{array}{c}\text { Nivel de } \\
\text { amenaza }\end{array}$ \\
\hline 0 a $-0,99$ & Sequía leve & 1 \\
\hline$-1,00$ a $-1,49$ & Sequía Moderada & 2 \\
\hline$-1,5$ a $-1,99$ & Sequía severa & 3 \\
\hline-2 y menos & Sequía extrema & 4 \\
\hline
\end{tabular}

Fuente: Modificado de Nasrollahi et al., (2018). 
- Recopilación de información y adquisición de datos

Se utilizó la información de precipitación de las estaciones pluviométricas a cargo de la Dirección General de Aguas y de la Dirección General de Aeronáutica Civil. En total se seleccionaron 17 estaciones pluviométricas (Figura 1). De estas, seis estaciones se localizan al interior de la cuenca del río Mataquito, el resto de las estaciones se ubican próximas al área de estudio y son consideradas de soporte, ya que se seleccionaron con el fin de obtener un SPI de mayor precisión y facilitar la interpolación.

\section{- Cálculo estadístico de los datos faltantes en estaciones pluviométricas}

Dada la falta de datos de las estaciones seleccionadas, estas se completan a través de la estimación de datos faltantes utilizando el método estadístico de regresión-correlación (OMM, 2006). La cual define una relación lineal entre dos variables y por medio de una gráfica de dispersión establece el grado de relación mediante el coeficiente de correlación que proporciona la Ecuación 2 que permite calcular el valor faltante en función del dato de la estación de referencia.

$$
\mathrm{Y}^{\wedge}=\mathrm{a}+\mathrm{b}^{*} \mathrm{X}
$$

Ecuación 2. Coeficiente de correlación. Fuente: Carrera-Villacrés et al. (2016).

Donde; $Y^{\wedge}=$ Valor estimado de la precipitación para la estación carente $(\mathrm{mm}) . x=$ Valor de precipitación registrado en la estación patrón $(\mathrm{mm}) . a, b=$ constantes de regresión.

En esta investigación se utilizó una estación vecina, dado que ninguna estación contaba con todos los datos requeridos; el método de regresión lineal se fue ajustando según la información de cada estación para obtener una correlación positiva de intensa a perfecta, reflejada en el valor de r, superior a 0,5 (CarreraVillacrés et al., 2016).

\subsection{Aplicación de un Índice de Vulnerabilidad a la Sequía}

Se utilizó el índice de vulnerabilidad de sequía (DVI) del tipo analítico, conformado a partir de la relación entre los indicadores de exposición, sensibilidad y adaptabilidad a la vulnerabilidad de sequía. Se seleccionaron siete variables (Tabla 3). Las cuales se ajustan al objetivo de la configuración del riesgo enfocado en el medio rural y la actividad agrícola.

Tabla 3. Indicadores y variables de vulnerabilidad a la sequía.

\begin{tabular}{|c|l|l|}
\hline $\begin{array}{c}\text { Indicadores de } \\
\text { Vulnerabilidad }\end{array}$ & \multicolumn{1}{|c|}{ Variables } & \multicolumn{1}{c|}{ Definición } \\
\hline \multirow{2}{*}{ Exposición } & Tierras de regadío & $\begin{array}{l}\text { Porcentaje de tierra irrigada sobre la superficie total de } \\
\text { tierra (Nasrollahi et al., 2018). }\end{array}$ \\
\cline { 2 - 3 } & Ocupación agrícola & $\begin{array}{l}\text { Porcentaje del terreno de uso agrícola respecto a la superficie } \\
\text { total distrital (FAO, 2010). }\end{array}$ \\
\hline \multirow{5}{*}{ Sensibilidad } & $\begin{array}{l}\text { Acceso a red de agua } \\
\text { pública }\end{array}$ & $\begin{array}{l}\text { Existe un nivel de pobreza al no contar con acceso de agua } \\
\text { potable mediante la red pública y con cañerías dentro de la } \\
\text { vivienda (Aponte, 2016). }\end{array}$ \\
\cline { 2 - 3 } & $\begin{array}{l}\text { Densidad de } \\
\text { población }\end{array}$ & $\begin{array}{l}\text { Número de personas por kilómetro cuadrado a nivel de } \\
\text { distrito censal (Nasrollahi et al., 2018). }\end{array}$ \\
\cline { 2 - 3 } & $\begin{array}{l}\text { Proporción } \\
\text { población rural }\end{array}$ & $\begin{array}{l}\text { Porcentaje de población rural a nivel distrital. Entendiendo } \\
\text { como rurales a las personas que habitan en localidades } \\
\text { con menos de 2.000 habitantes (Instituto Nacional de } \\
\text { Estadísticas [INE],2017). }\end{array}$ \\
\hline
\end{tabular}




\begin{tabular}{|l|l|l|}
\hline Adaptabilidad & $\begin{array}{l}\text { Diversificación } \\
\text { Productiva }\end{array}$ & $\begin{array}{l}\text { Cantidad de rubros productivos asociados a la agricultura a } \\
\text { nivel distrital según censo agropecuario. (FAO, 2010). }\end{array}$ \\
\cline { 2 - 3 } & $\begin{array}{l}\text { Adaptabilidad } \\
\text { tecnológica }\end{array}$ & $\begin{array}{l}\text { Infraestructura adecuada para enfrentar el evento de sequía } \\
\text { (FAO, 2010). } \\
\text { Se compone de dos factores; tipo de riego (tecnificado o } \\
\text { convencional) y tipo de maquinarias agrícolas (maquinaria } \\
\text { de tiro animal, maquinaria de tiro mecanizado y maquinaria } \\
\text { estacionaria). }\end{array}$ \\
\hline
\end{tabular}

Fuente: modificado de Shahid y Behrawan, 2008; FAO, 2010; Vargas \& Paneque, 2017; Nasrollahi et al., 2018.

\subsubsection{Cálculo DVI: Asignación de peso y Evaluación Multicriterio}

A cada una de las variables se les definieron cuatro niveles, según el indicador de vulnerabilidad al que pertenecen. Utilizando el método de ruptura natural de ArcGIS para extraer las clases (Nasrollahi et al., 2018), las cuales se clasifican como; bajo, moderado, severo y extremo.

Para la variable adaptabilidad tecnológica, que se compone de dos factores previamente se realizó la ponderación de los factores mediante el proceso de jerarquía analítica de Saaty y el análisis de componentes principales en la cual se le otorgó un valor de 0,25 a cada una de las categorías (Che et al. 2010, como se citó en Belal et al., 2014).

Estas variables se calcularon y normalizaron mediante el método estándar de desviación media y el método min-máx., para realizar la integración mediante la asignación de peso a todos los factores según el Proceso de Jerarquía Analítica de Saaty con base en lo expuesto por Nasrollahi et al. (2018).

Los valores de DVI oscilan entre 0 (apenas vulnerable) y 1 (muy vulnerable). Lo cual indica priorización de entidades vulnerables. Con esto se obtiene los índices relativos para cada componente. La importancia relativa de cada componente en el DVI está indicada de acuerdo con una serie de categorías de rangos de valores (ponderación) y clasificación (Tabla 4).

Tabla 4. Índice de Importancia Relativa DVI.

\begin{tabular}{|c|c|}
\hline Grado de Vulnerabilidad & Peso \\
\hline Bajo & 1 \\
\hline Moderado & 2 \\
\hline Severo & 3 \\
\hline Extremo & 4 \\
\hline
\end{tabular}

Fuente: modificado de Nasrollahi et al. (2018); Vargas \& Paneque (2017).

La ponderación de cada factor se realizó a través de técnicas de evaluación Multicriterio EMC, mediante el método de jerarquías analíticas de Saaty (Ni \& Gu, 2005, como se citó en Belal et al., 2014). Los valores del DVI, para cada indicador de la vulnerabilidad, se realizó a través del proceso analítico Weighted Overlay, que integra los respectivos pesos y ponderaciones anteriormente evaluados, lo cual se expresa como:

$$
\mathrm{IDH}=\sum_{i=0,45}^{3} \exp +0,40 \operatorname{sen}+0,15 a d p
$$

Ecuación 3.

Donde, exp corresponde a exposición, sen a sensibilidad y adp a adaptabilidad.

\section{Resultados}

\section{1. Índice de Amenaza de Sequía Meteorológica}




\subsection{1. Índice de Precipitación Estandarizada SPI}

Se presentan y analizan los resultados del SPI de las estaciones al interior de la cuenca. De forma general se aprecia que los valores del SPI se tienden a concentrar en categoría media, con clasificación que varía entre normal, moderadamente húmedo y moderadamente seco.

Se observa en el gráfico de SPI anual (Figura 2), que desde 1979 hasta 1995 se registraron períodos normales con tendencia a húmedo. El primer periodo de evento climático ocurrió entre los años 1981 y 1983, catalogado como un periodo húmedo, en 1982 se registra un SPI de clasificación muy húmedo, siendo uno de los valores SPI más alto en todo el tiempo de estudio.

Un segundo periodo entre los años 1995 y 1999 corresponde a lo relacionado con los periodos secos, asociados a déficit de precipitación. En el año 1996 se registra el primer evento de sequía con SPI de categoría moderadamente seca, situación que cambia rápidamente, ya que, al año siguiente, se registra un SPI de categoría moderadamente húmedo. Este vuelve a cambiar, puesto que al año 1998 se clasifica el valor del índice como extremadamente seco, con un valor SPI de -2,50, siendo el valor más bajo registrado en los 41 años de estudio. Para el año siguiente, 1999 se registra un valor de SPI de categoría normal, se estima que el periodo de sequía fue de un año, dado que se vuelve a obtener un valor positivo.

En tanto para la década del 2000, se identifica un tercer periodo para los años 2000 y 2010, que se caracteriza por dos periodos húmedos y un periodo seco. El periodo húmedo se registra entre los años 2002 y 2005 donde el valor del SPI alcanza categoría de muy húmedo y moderadamente húmedo, respectivamente. En el año 2002 se registra el valor más alto de SPI 1,56, situación que al año siguiente cambia y se obtiene una clasificación de SPI Normal seco, volviendo a un periodo de normalidad. El periodo seco se caracteriza por registrar en el año 2007 un SPI de valor negativo, alcanzando la categoría moderadamente seca, el cual cambia a normal en 2008 hasta 2010, marcando el comienzo de un cuarto periodo entre 2010- 2019, catalogado como "megasequía".

Figura 2. Gráfico SPI anual, Cuenca río Mataquito.

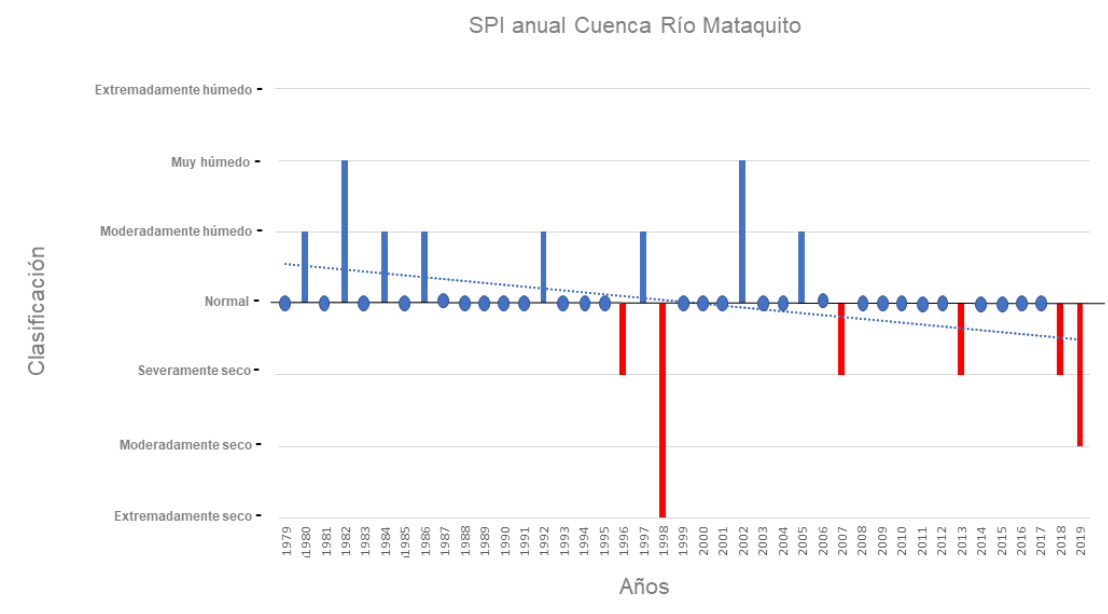

Fuente: elaboración propia a partir de resultados SPI DrinC.

En el cuarto periodo correspondiente a la megasequía se registra la mayor secuencia de valores SPI negativo, entre los años 2010-2012 se evidencia que la precipitación fue menor que la mediana, correspondiente a períodos secos, lo cual condiciona que para el año 2013 se calcule el primer periodo de sequía, alcanzando la intensidad de $-1,10$ con categoría de moderadamente seco, este episodio de sequía finalizó al año siguiente, donde la intensidad calculada fue de 0,08 , periodo de precipitación mayor que la media y que por ende se cataloga como normal, sin embargo, esta intensidad registrada es el único valor positivo en el periodo de tiempo de la megasequía. Luego, desde el año 2015 al 2019 se obtuvieron valores negativos, lo cual indica que durante cinco años consecutivos se ha registrado una precipitación inferior que la media y que desde el año 2018 comienza un periodo de sequía de intensidad $-1,18$ y categoría moderadamente seca, la cual se intensifica en el 2019 aumentando a la categoría severamente seco, con un valor de -1,91. Para los años 2020 y 2021, se estima que dicha tendencia no ha sufrido variaciones.

De los resultados del SPI, es posible identificar diversos periodos de eventos climáticos los cuales 
coinciden con registros del ciclo ENOS, oscilación de fase cálida (El Niño) y una fase fría (La Niña). En Chile, la fase del Niño se caracteriza por severas precipitaciones asociado con un calentamiento del océano Pacífico ecuatorial central y oriental. Por el contrario, durante la fase de La Niña se registra un enfriamiento del océano, intensificación de los vientos alisios en el este del océano Pacífico y períodos de sequía (Maturana et al., 1997). Los eventos de precipitaciones excepcionales más intensos se registraron en 1982-1983 y 1997-1998 (Arntz \& Fahrbach, 1996; Dillon 1998, como se citó en Muñoz-Schick et al., 2001). Mientras que los años secos que por lo general ocurren en forma aislada, se han presentado en los años 1988 a 1990 y 2010 a $2015\left(C R^{2}, 2015\right)$.

\subsubsection{Resultado Índice de Amenaza de Sequía Meteorológica}

De la interpolación del SPI en la cuenca del río Mataquito se obtiene la clasificación espacial del nivel de amenaza (Figura 3). Se identifica que el sector de costa, correspondiente a la cuenca baja, posee un nivel de amenaza extremo al fenómeno de sequía meteorológica, abarca una superficie de $640 \mathrm{~km}^{2} \mathrm{y}$ representa al 10,2\% de la superficie de la cuenca. El nivel de amenaza severo al fenómeno de sequía abarca una superficie de $1.445,7 \mathrm{~km} 2$ y se localiza en los sectores con mayor altitud, abarcando tanto la Cordillera de la Costa, así como también, la de Cordillera de los Andes. En conjunto estos niveles de amenaza se consideran los más preocupantes, ya que son los más susceptibles a las condiciones del peligro de sequía.

Por el contrario, los niveles de amenaza bajo y moderado se localizan principalmente en el sector del valle central, precordillera y cordillera, abarcan el 66,6\% de la superficie de la cuenca. El nivel moderado tiene una superficie de $2.008 \mathrm{~km}^{2}$. Por su parte, el nivel de amenaza bajo, representa la mayor cantidad de superficie de la cuenca, abarca aproximadamente $2.161 \mathrm{~km}^{2}$ y se distribuye por el valle, sector donde se localizan los principales asentamientos humanos, grandes centros urbanos y la zona por excelencia de la actividad agrícola nacional.

Figura 3. Índice de Amenaza de Sequía Meteorológica.

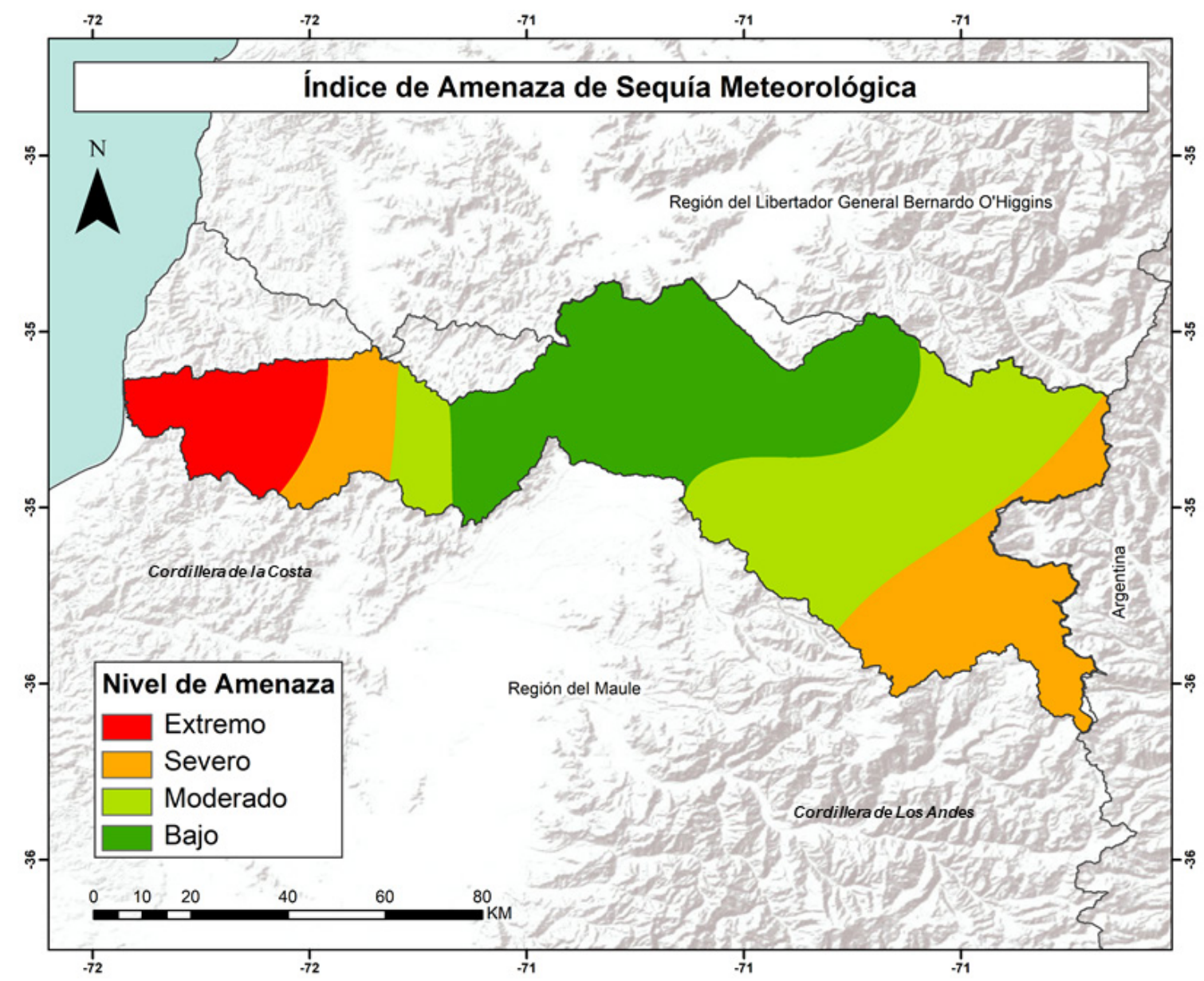

Fuente: elaboración propia. 


\section{2. Índice de Vulnerabilidad de Sequía Meteorológica}

\subsubsection{Exposición}

El indicador de exposición (Figura 4-a) resultado de la ponderación de las variables ocupación agrícola y tierra de regadío. Se obtuvo que los niveles más altos de exposición correspondiente a las categorías de severo y extremo abarcan el 19\% del total de la superficie de la cuenca, con una superficie de $518,2 \mathrm{~km}^{2}$ y $714 \mathrm{~km}^{2}$ respectivamente, se concentran en el sector de la cuenca media, zona donde se desarrolla principalmente la actividad agrícola evidenciada en la variable ocupación agrícola, lo cual producto de las condiciones climáticas y del suelo propician un lugar perfecto para estas prácticas. Por el contrario, el $81 \%$ de la cuenca no presenta niveles preocupantes de exposición, estos niveles se localizan en el sector de cuenca alta y baja, correspondiente a los sectores cordilleranos con condiciones climáticas y geomorfológicas que no son propicias para el desarrollo de la actividad agrícola o que implican un gran esfuerzo para llevarla a cabo.

Respecto a la variable ocupación agrícola, los niveles severo y extremo se localizan en la zona del valle central, el nivel extremo abarca una superficie de $456,7 \mathrm{~km}^{2}$ y corresponden a porcentajes de ocupación entre el 65 y 100\%, el nivel severo presenta una superficie de $271,4 \mathrm{~km}^{2}$ con porcentajes entre los 25 y 65\%. Por el contrario, los niveles moderados y bajo abarcan una mayor superficie, el nivel moderado tiene una superficie de $239,7 \mathrm{~km}^{2}$ con porcentajes de ocupación agrícola entre los 10 y $25 \%$, mientras que el nivel bajo representa la mayor cantidad de superficie, con un total de $5.282,5 \mathrm{~km}^{2}$ que corresponde entre el 0 y $10 \%$ de ocupación agrícola, es decir, que en estas zonas la actividad agrícola es inexistente y/o de muy menor tamaño. Espacialmente se distribuyen en la zona cordillerana y sector costero, correspondiente a la parte alta y baja de la cuenca.

La variable tierras de regadío, presenta resultados similares a los obtenidos en ocupación agrícola. Las categorías con menor nivel expresan que existe un porcentaje bajo de tierra irrigada en relación a la superficie distrital, dado que la ocupación agrícola es menor. Los niveles bajo y moderado abarcan una superficie de $2.965 \mathrm{~km}^{2}$ y $2.239,7 \mathrm{~km}^{2}$ respectivamente, mientras que los niveles severo y extremo poseen $647 \mathrm{~km}^{2}$ y $397,5 \mathrm{~km}^{2}$ de tierras de regadío respecto a la superficie distrital.

\subsubsection{Sensibilidad}

Las variables que conforman al indicador de sensibilidad definen características propias del medio rural de la región, que se caracteriza por una alta ruralidad, densidades bajas de población y dificultades al acceso a la red de pública de agua potable.

De la superposición de las tres variables (Figura 4-b) se obtiene que, 31 distritos presentan categorías bajas de sensibilidad ante la vulnerabilidad del riesgo de sequía meteorológica, 11 poseen un nivel bajo y 20 un nivel moderado. De manera preocupante, 33 distritos presentan mayor sensibilidad ante el fenómeno, de los cuales, 15 con nivel severo y 18 a nivel extremo, representando en conjunto al 79\% de la cuenca. Se identifica que, en la zona cordillerana y cuenca alta, se concentran las categorías más altas, como también en el sector costero de la cuenca baja en el cual se concentran una gran cantidad de distritos de nivel extremo, por el contrario, los distritos de categorías bajas, tienden a distribuirse en la zona de cuenca media, correspondiente al valle central.

De la variable acceso a la red de consumo de agua, se obtiene que la categoría de sensibilidad extrema al acceso de red de agua pública corresponde al 23,3\% de la superficie de la cuenca y abarca a aquellos distritos que entre el $70 \%$ y $100 \%$ de sus habitantes no poseen conexión a la red de agua, en total se identificaron 748 viviendas de siete distritos del tipo rural que se abastecen mediante agua del río, camiones aljibes y/o de pozo o noria. En tanto, la categoría severa representa el 20,4\% de la superficie, con un total de cinco distritos en que el $60 \%$ de sus habitantes no cuentan con accesibilidad a la red de agua.

Por el contrario, la categoría de sensibilidad baja a la vulnerabilidad de acceso de red de agua, abarca el 23,9\% de la superficie de la cuenca, mientras que la categoría moderada abarca el 32,2\% de la superficie. En estos distritos el $80 \%$ de sus habitantes cuentan con conexión, corresponde a la mayor cantidad de distritos distribuidos en los sectores de cuenca media y baja. Destaca que más del $90 \%$ de las viviendas del área de estudio cuentan con conexión a la red pública de agua, pero tan sólo un distrito cuenta con el 100\% de conexión a la red, que corresponde a tipo urbano en la ciudad de Curicó.

En cuanto a la variable proporción población rural a urbana, se identificaron 34 distritos con un $100 \%$ de población rural, lo que representa una sensibilidad de nivel extremo ante la vulnerabilidad de 
sequía. A pesar de que la cantidad de habitantes urbanos es mucho mayor que los habitantes rurales según los datos obtenidos desde el censo 2017, la cuenca del río Mataquito, cuenta con un total de 78.257 habitantes rurales y 212.383 habitantes urbanos. La mayoría de los distritos se consideran rurales o mixtos, siendo más sensibles a la sequía meteorológica, ya que es en estas zonas donde se desarrolla la actividad agrícola y se presentan importantes brechas respecto a las zonas urbanas.

Por último, los resultados de la variable densidad de población, indican que gran porcentaje de la cuenca no posee categorías altas de sensibilidad y que estas se localizan en sectores costeros y cordilleranos, mientras que los distritos con niveles severo y extremos se localizan en la depresión central y se concentra en aquellos distritos de carácter urbanos, siendo el distrito Licantén de Curicó el que presenta mayor densidad, con un total de 4.513 habitantes por $\mathrm{km}^{2}$. Por el contrario, cinco de los distritos con menor densidad no superan 1 habitante por km2. Localizados en sectores precordilleranos y cordilleranos de gran superficie que dificultan el asentamiento y desarrollo humano.

\subsubsection{Adaptabilidad}

Los resultados del indicador de adaptabilidad (Figura 4-c) reflejan que de manera general la cuenca y los distritos poseen altos niveles de tecnificación, dado que se tienden a concentrar en los niveles de vulnerabilidad de adaptabilidad bajo y moderado. Por el contrario, tan solo seis distritos presentaron un nivel extremo de adaptabilidad, estos abarcan 305,5 $\mathrm{km}^{2}$ de la cuenca equivalente a un 4,8 \% de esta.

El factor riego tecnificado de la variable adaptabilidad tecnológica, es uno de los ejes principales para la disminución de la vulnerabilidad a la sequía, ya que con este se puede obtener un rendimiento eficiente del recurso y evitar pérdidas. Por el contrario, el riego tradicional o por gravedad, el cual consiste en la distribución del agua a través de canales o surcos, es el sistema de riego más económico pero que depende totalmente del conocimiento del agricultor/a, posee limitaciones al utilizarlo y puede generar un desaprovechamiento del agua.

La cuenca frente a este factor, presenta un nivel preocupante, ya que el 71\% de la superficie irrigada es realizada mayoritariamente por medio del riego del tipo tradicional, representada en los niveles de adaptabilidad severo y extremo. Los distritos con mayor superficie de riego, poseen como principal sistema de riego el del tipo tendido, considerado el sistema de riego más ineficiente en actualidad. Por el contrario, tan solo cuatro distritos, cuentan con más del 50\% de su superficie de riego del tipo tecnificado.

El factor de maquinarias agrícolas, tales como; equipos y maquinaria estacionaria, maquinaria de tiro animal y tiro mecanizado. Conforman la mecanización agrícola, considerado como un instrumento de gestión de la agricultura, dado que la mecanización y/o industrialización produce un aumento de los rendimientos de los cultivos y el potencial de producción de sus recursos. Es así como, la maquinaria de tiro animal representa mayor grado de vulnerabilidad dado que los animales se ven fuertemente afectado por el fenómeno de sequía. En la cuenca, se registran 11.783 maquinarias tiro animal versus 15.009 del tipo de tiro mecanizado, cifras que permiten identificar un alto grado de vulnerabilidad según capacidad de adaptabilidad.

El conjunto de la tecnificación de riego más la tecnificación en las maquinarias de producción dan como resultado la adaptabilidad tecnológica. Los valores preocupantes de vulnerabilidad de adaptabilidad tecnológica, de categoría severo y extremo se localizan en los sectores de costa y cordillera, abarcan el 72,7\% de la superficie de la cuenca poseen una superficie de $3.046,5 \mathrm{~km}^{2}$ y $1.498,5 \mathrm{~km}^{2}$ respectivamente. Mientras que la zona del valle central, concentra mayormente categorías de mejor adaptabilidad, presentando una vulnerabilidad baja a verse afectado por el fenómeno de sequía. La categoría bajo posee una superficie de $570,4 \mathrm{~km}^{2}$ mientras que la categoría moderada de $1.134,5 \mathrm{~km}^{2}$. Lo cual se relaciona a que es en este sector donde se desarrolla la actividad agrícola de grandes producciones.

En cuanto a la variable diversificación productiva, que identifica la cantidad de rubros por unidad distrital, tiene como resultado niveles altos de adaptabilidad, ya que, existe una gran variedad de cultivo, los valores bajo y moderado abarcan al más del $90 \%$ de la superficie de la cuenca, lo cual significa que se desarrollan más de cinco tipos de cultivos diferentes. Por el contrario, la categoría de vulnerabilidad extrema de adaptabilidad, que significa que no hay más de dos tipos de cultivos, representa el 0,1\% de la superficie de la cuenca correspondiente a $9,4 \mathrm{~km}^{2}$. 
Figura 4. Indicadores de Vulnerabilidad. Indicador de exposición b) Indicador de sensibilidad c) Indicador de Adaptabilidad

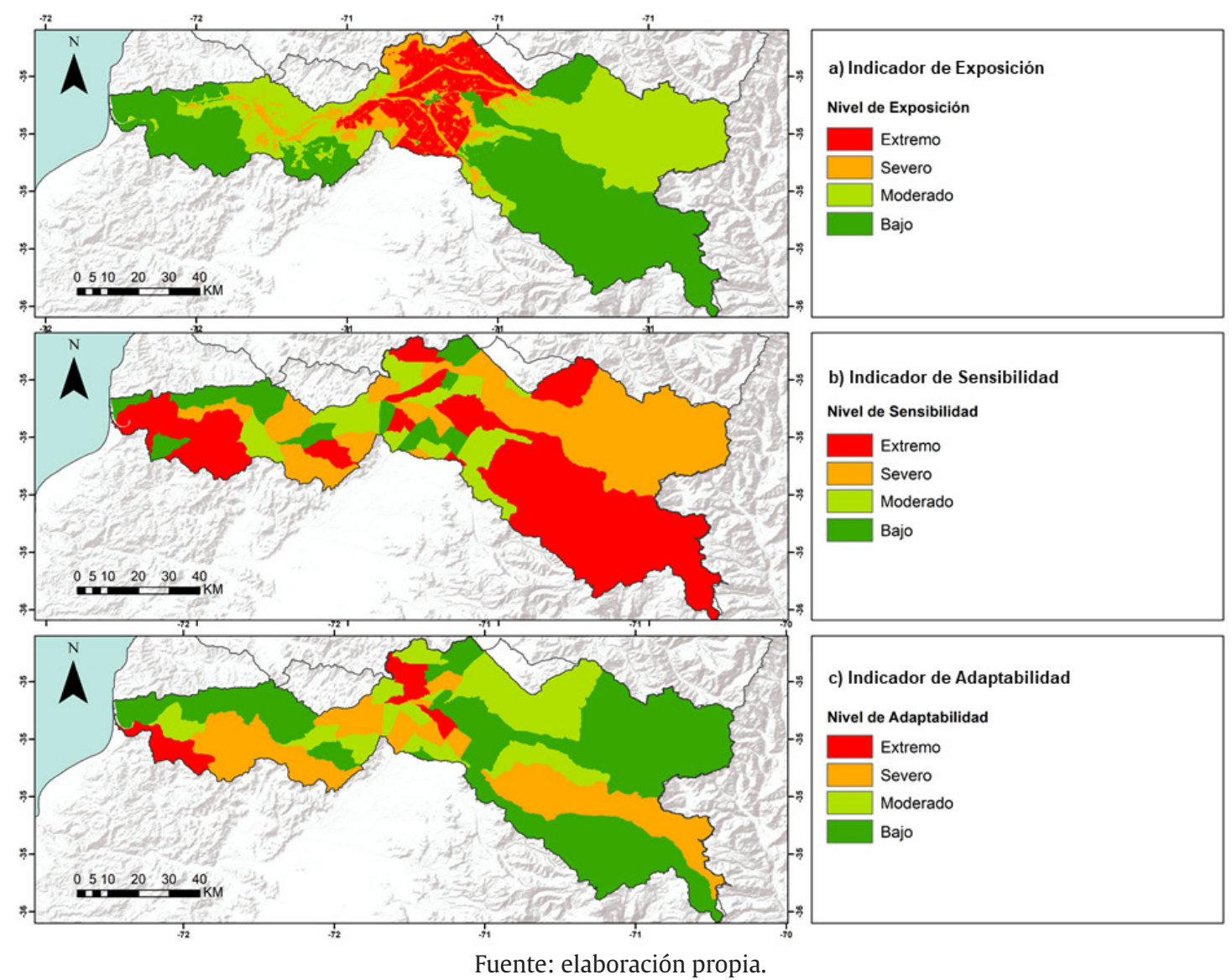

\subsubsection{Resultado Índice de Vulnerabilidad}

El resultado de la ponderación de los tres componentes de la vulnerabilidad (Figura 5) indica que la cuenca del Río Mataquito presenta un DVI concentrado mayoritariamente entre los niveles bajo y moderado, cuyas superficies corresponden a $3.101 \mathrm{~km}^{2}$ y $1.271 \mathrm{~km}^{2}$ respectivamente, equivalentes al $69 \%$ de la cuenca. Por el contrario, las categorías preocupantes de vulnerabilidad de niveles severo y extremo, abarcan una superficie de $1.656 \mathrm{~km}^{2}$ y $219 \mathrm{~km}^{2}$ respectivamente.

En cuanto con la división distrital, seis distritos presentan una vulnerabilidad a la sequía meteorológica de carácter extremo. Estos corresponden a los distritos ubicados en la zona de costa, Huenchullamí, Curepto y El Manzano de Curepto, de la comuna de Curepto y a los distritos de la zona del valle, Tutuquén y La Obra, pertenecientes a la comuna de Curicó. 
Figura 5. índice de vulnerabilidad a la sequía.

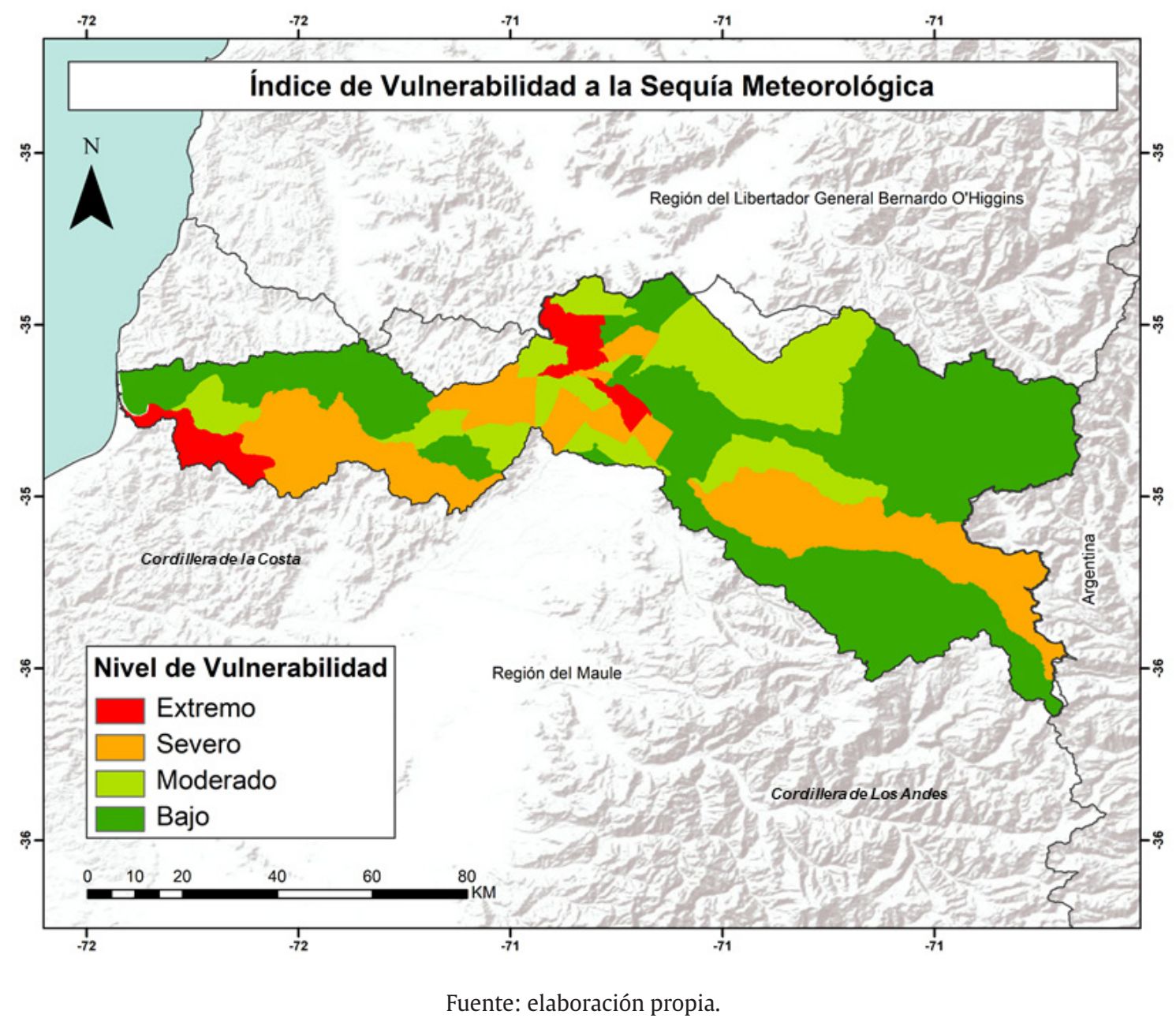

\section{3. Índice del Riesgo de Sequía - DRI}

El índice revela el riesgo de sequía en la cuenca del río Mataquito, identificados y espacializados según niveles de susceptibilidad al riesgo de sequía meteorológica mediante la categorización bajo, moderado, severo y extremo.

El resultado expresado la cartografía (Figura 6) indica que, en relación con las superficies según el nivel de riesgo se obtiene que la cuenca en un 49,6\% presenta un nivel de riesgo bajo, distribuido principalmente en la parte alta de la cuenca, la cual se caracteriza por la presencia de la cordillera de Los Andes, lo cual influye en que no se desarrollen grandes asentamientos ni la actividad agrícola dada limitaciones continuas que no pueden ser corregidas. Destaca también el sector de cuenca baja, localizado al noroeste, que presenta niveles bajo de riesgo, este sector costero no presenta gran actividad de la agricultura sino más bien destaca por la actividad forestal.

El nivel moderado abarca una superficie de $1.271 \mathrm{~km}^{2}$ correspondiente al 20,3\% de la superficie de la cuenca, se manifiesta principalmente en la parte de cuenca media, incluyendo sectores precordilleranos y de costa.

En cuanto a los niveles más preocupantes, un 3,5\% de la superficie de se ve expuesta al riesgo de sequía de manera extrema, a nivel distrital esto corresponde a cinco de los 64 distritos, de los cuales tres se localizan en el sector costero inferior de la cuenca, correspondiente a la comuna de Curepto y los dos restantes en la zona del valle central, de la comuna de Curicó. Las características de la zona, expresada en los índices tanto de peligro como de vulnerabilidad se conjugan de forma negativa y resultan en escenarios de extremo riesgo de sequía meteorológica. En tanto, la categoría de severo riesgo a sequía, se manifiesta en un $26,5 \%$ del área de estudio, se distribuye en distritos del valle central y por el sector cordillerano costero, destaca un distrito de gran superficie de riesgo severo que se localiza en el sector de la cordillera andina. 
Los distritos de nivel extremo ubicados en la zona del valle central, presentan gran actividad agrícola y poseen niveles altos de exposición a la vulnerabilidad como también de adaptabilidad, desatacando el nivel de severidad en la categoría del riesgo tecnificado. Por su parte, el indicador de sensibilidad, presenta los niveles menos preocupantes, ya que la variable más importante de acceso a la red pública de agua presenta niveles bajo de vulnerabilidad, solamente es alto la ruralidad, algo común del área de estudio. En cuanto la influencia de la amenaza de sequía meteorológica, este sector se encuentra en niveles bajo, pero como se ha mencionado, las precipitaciones tienden a la baja en todo el sector de la cuenca provocando incertidumbre en un futuro.

El restante de distritos localizados en la parte baja de la cuenca no poseen niveles graves de exposición, ya que no hay gran desarrollo de la actividad agrícola en dicho sector, pero sí poseen niveles graves de sensibilidad, destacando la variable de acceso a la red de agua pública, que presenta estos niveles altos. En cuanto a la adaptabilidad, esta también posee niveles graves, influenciado principalmente por la variable adaptabilidad tecnológica. Los niveles alto del riesgo a la sequía se debe principalmente a que es en este lugar donde el nivel de amenaza a la sequía meteorológica es más grave, influenciado por episodios de sequía que se manifiestan principalmente en este sector y con datos meteorológicos que indican una notable disminución de la precipitación durante los últimos años.

Figura 6. índice Integrado de Riesgo a la Sequía Meteorológica.

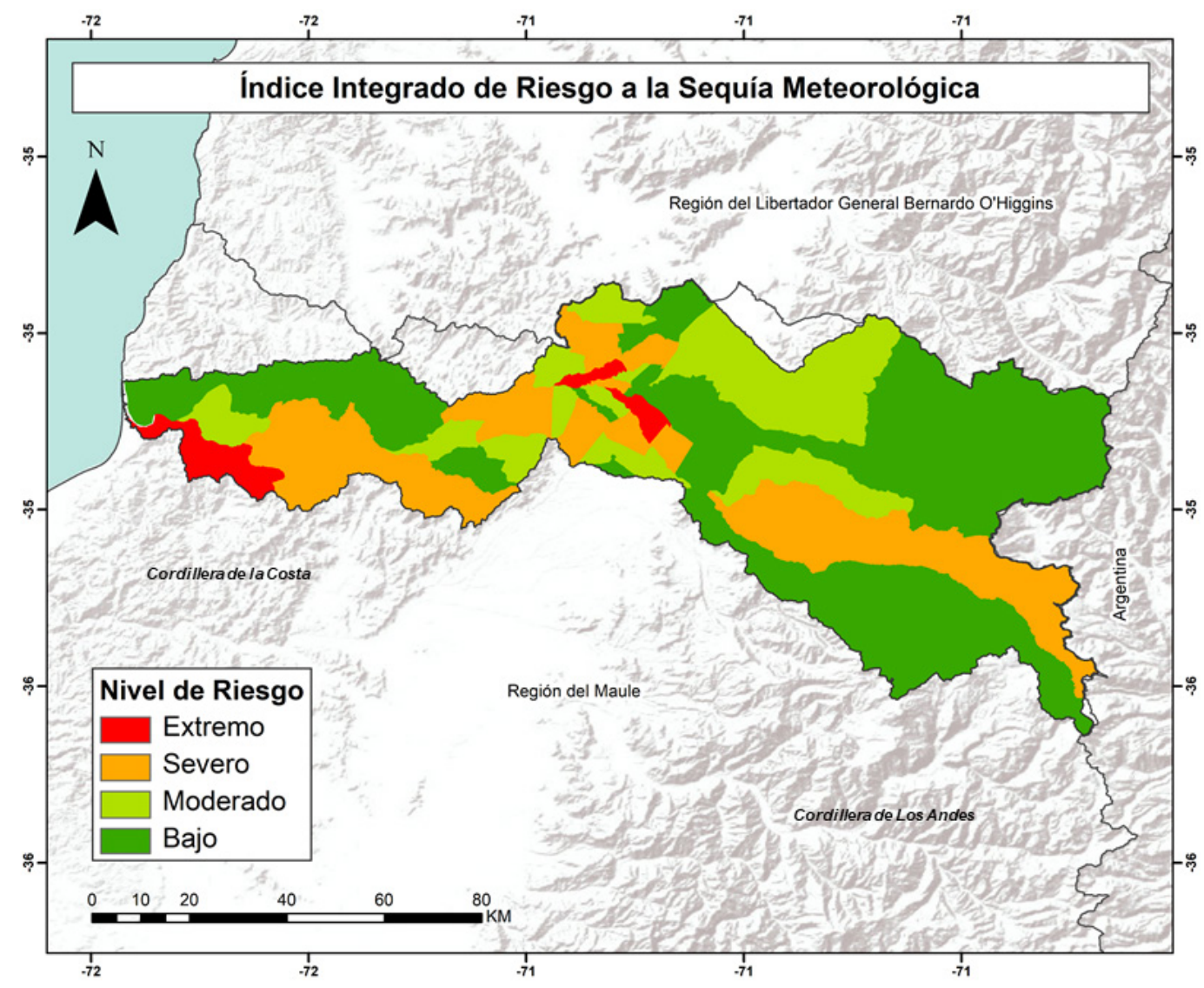

Fuente: elaboración propia.

\section{Conclusiones}

El procedimiento llevado a cabo para la elaboración y aplicación del índice integrado del riesgo a la sequía meteorológica en la cuenca del Río Mataquito implicó un encadenamiento metodológico para la selección e identificación de indicadores y variables para la conformación del índice, el cual fue diseñado bajo el concepto de riesgo, que se entiende como la confluencia de la amenaza y la vulnerabilidad. Este ejercicio, se realizó de forma integral, simple y a partir de datos de libre acceso. Se investigaron las condiciones locales que justifican la concepción de amenaza entendida como la disminución de precipitación que fue evaluada a través del SPI y de la vulnerabilidad enfocada en la actividad agrícola y del medio rural en función de los factores de exposición, sensibilidad y capacidad de adaptación. Lo 
anterior permitió la espacialización e identificación de niveles de riesgo en la cuenca, mediante evaluación multicriterio de ArcGIS.

Considerando que los estudios sobre riesgo de sequía son ampliamente abordados y cada vez existe más interés en realizar estudios e investigaciones, no existe una metodología única y general para evaluar el riesgo de sequía, sin embargo, existe cierto consenso en el uso del índice SPI (OMM,2012; Rahman \& Lateh, 2016; Zhao et al., 2020). Sin embargo, todos los índices presentan limitaciones, ya que la gran mayoría de ellos son univariantes dado que estos consideran solo una forma física particular de sequía, a pesar de que pueden existir múltiples sequías simultáneamente (Rajsekhar et al., 2015).

Otro aspecto relevante que es necesario mencionar, es la gran variedad de estudios y la aplicación de diversas metodologías, que generan un amplio espectro de predictores del riesgo de sequía. No obstante, existen paradigmas comunes, que permiten una recomendación general del estudio de riesgo, estas son la evaluación de amenaza, vulnerabilidad e impacto en el marco de un modelo estadístico. Aun así, es esencial avanzar hacía un enfoque integral que considere todas las formas físicas de sequía en su conjunto.

Los resultados del SPI permiten identificar periodos de características húmedos y secos que presentan relación con los ciclos de ENOS expuestos anteriormente, sin embargo, se estima que el fenómeno ocurre por lo general en intervalos de 3 a 7 años (Maturana et al., 1997) situación que genera preocupación con el cuarto periodo identificado entre 2010-2019, ya que, en este tiempo se registran la mayor secuencia de valores SPI negativo. En los años 2010-2012 se identifican períodos secos y en el 2013 el primer periodo de sequía de categoría moderadamente seco. Desde el año 2015 al 2019 se obtienen valores negativos con un registro de precipitación inferior a la normal y desde el año 2018 comienza un periodo de sequía de categoría moderadamente seca, la cual se intensifica en el 2019 aumentando a la categoría severamente seco.

En cuanto al índice de vulnerabilidad, este se encuentra estrechamente relacionado con la infraestructura humana y las condiciones socioeconómicas, motivo por lo cual se considera que el efecto del fenómeno de la sequía en las zonas rurales es más severo, derivando en importantes desafíos para la economía rural en general y la producción agrícola en particular. La cuenca presenta un gran desarrollo de la actividad agrícola, siendo un considerado aporte al PIB nacional, al mismo tiempo, el rubro agrícola representa la mayor tasa de ocupación laboral en la región y por ende del modo de vida de gran parte de los habitantes. De ello se concluye que el desarrollo de la actividad agrícola es esencial en la cuenca del Río Mataquito y que la evaluación de la vulnerabilidad para la reducción del riesgo significa grandes ventajas para el desarrollo.

Los resultados obtenidos al aplicar el índice del riesgo a la sequía meteorológica en la cuenca del Río Mataquito indican que tan solo un 3,5\% de la superficie se ve expuesta al riesgo de sequía de manera extrema, se localiza en distritos costeros de la cuenca y en el valle central correspondiente a distritos del tipo mixtos y rurales. En tanto, la categoría de severo riesgo a la sequía se manifiesta en un $26,5 \%$ y representa la segunda categoría con mayor superficie. La categoría baja concentra la mayor cantidad de distritos y de superficie al interior de la cuenca, mientras que la categoría moderada concentra distritos en la zona noreste de la cuenca, abarcando espacialmente la zona de cuenca media.

Se considera que la relación entre el riesgo de sequía meteorológica con aquellos sectores rurales de gran desarrollo de la actividad agrícola del valle central mencionada en la hipótesis es más bien débil, ya que tan solo dos distritos de este sector presentan nivel de extremo riesgo, mientras que el resto de distritos poseen niveles de severo y moderado. Por el contrario, la zona de cuenca baja correspondiente a sectores costeros del suroeste de esta, se evidencia claramente mayores niveles de riesgo. Esto se debe a que la vulnerabilidad es evaluada mediante tres indicadores que identifican diversas características. Así bien, el sector del valle central presenta niveles altos de exposición, no ocurre lo mismo con los niveles de sensibilidad y adaptabilidad que se concentra en los niveles bajos. Considerando, además, que el nivel de amenaza de sequía meteorológica en el valle central es bajo, ya que los valores de SPI que, si bien concentran una disminución general, la desviación de los datos de este sector es menor que en aquellos sectores de cuenca baja donde se localizan los niveles más altos de amenaza.

Se concluye de tal forma que, si la actividad agrícola presenta altos niveles de exposición a la vulnerabilidad de sequía esta no representa mayores niveles de susceptibilidad al riesgo de sequía meteorológica si los niveles de los indicadores de adaptabilidad y sensibilidad son bajos, en especial sus variables vinculadas al riego tecnificado, diversificación productiva y acceso a la red de agua.

El índice integrado del riesgo a la sequía meteorológica permitió identificar las áreas con riesgo de sequía extrema evidenciando una relación entre el modo de desarrollo de la actividad agrícola, el estado del sistema territorial y la sequía. En este contexto y ante el actual escenario que vive el país, esta propuesta es una contribución para la toma de decisiones y la planificación, ya que permite focalizar zonas estratégicas 
para la gestión del riesgo para el monitoreo en el corto, mediano y largo plazo.

\section{Referencias bibliográficas}

Aneas de Castro, S. (2000). Riesgos y peligros: una visión desde la geografía. Scripta Nova, Revista Electrónica de Geografia y Ciencias Sociales, 4(60). http://www.ub.edu/geocrit/sn-60.htm

Aponte Gómez, C., Romero Aroca, E. M., y Santa Guzmán, L. F. (2016). Análisis de datos espaciales del Índice de Necesidades Básicas Insatisfechas en la Región Andina. Perspectiva Geográfica, 20(2), 391-418. https://doi.org/10.19053/01233769.4533

Belal, A.A., El-Ramady, H.R., Mohamed y Saleh, A.M. (2014). Drought risk assessment using remote sensing and GIS techniques. Arab J Geosci,7, 35-53. https://doi.org/10.1007/s12517-012-0707-2

Cardona, O. D. (1993). Evaluación de la amenaza, la vulnerabilidad y el riesgo. Elementos para el ordenamiento y la planeación del desarrollo. En A. Maskrey (Ed.), Los desastres no son naturales (pp.51-74). LA RED, Tercer Mundo Editores. https://bit.ly/3lVwR9o

Cardona, O. D. (2001). Estimación holística del riesgo sísmico utilizando sistemas dinámicos complejos. [Tesis doctoral, Universitat Politècnica de Catalunya, Barcelona, España].http://hdl.handle.net/2117/93531

Carrera-Villacrés, D. V., Guevara-García, P.V., Tamayo-Bacacela, L.C., Balarezo-Aguilar, A. L., Narváez-Rivera, C. A. y Morocho-López, D. R. (2016). Relleno de series anuales de datos meteorológicos mediante métodos estadísticos en la zona costera e interandina del Ecuador, y cálculo de la precipitación media. Idesia (Arica), 34(3), 81-90. http://dx.doi.org/10.4067/S0718-34292016000300010

Castillo-Castillo, M., Ibáñez-Castillo, L., Valdés, J., Arteaga-Ramírez, R, y Vázquez-Peña, M. (2017). Análisis de sequías meteorológicas en la cuenca del río Fuerte, México. Tecnología y ciencias del agua, 8(1),3552. https://doi.org/10.24850/j-tyca-2017-01-03

Centro de Ciencia del Clima y la Resiliencia. (2015). Informe a la Nación. La mega sequía 2010-2015: Una lección para el futuro. https://bit.ly/3i0mCzf

Dirección General de Aguas. (2004). Diagnóstico y clasificación de los cursos y cuerpos de agua según objetivos de calidad: Cuenca río Mataquito. https://mma.gob.cl/wp-content/uploads/2017/12/ Mataquito.pdf

Garreaud, R., Boisier, JP., Rondanelli., Montecinos, A., Sepúlveda, H. and Veloso-Águila. D. (2019). The Central Chile Mega Drought (2010-2018): A climate dynamics perspective. International Journal of Climatology, 40(1),421-439. https://doi.org/10.1002/joc.6219

Gómez Orea, D. y Gómez Villa, A. (2013). Ordenación territorial. Mundi-prensa.

Intergovernmental Panel on Climate Change. (2007). Climate Change 2007: Impacts, Adaptation and Vulnerability. Contribution of Working Group II to the Fourth Assessment Report of the Intergovernmental Panel on Climate Change. https://www.ipcc.ch/site/assets/uploads/2018/03/ ar4_wg2_full_report.pdf

Intergovernmental Panel on Climate Change. (2012). Managing the Risks of Extreme Events and Disasters to Advance Climate Change Adaptation. Special Report of Working Groups I and II of the Intergovernmental Panel on Climate Change. https://www.ipcc.ch/site/assets/uploads/2018/03/ SREX_Full_Report-1.pdf

Intergovernmental Panel on Climate Change. (2014). Cambio climático 2014: Informe de síntesis. Contribución de los Grupos de trabajo I, II y III al Quinto Informe de Evaluación del Grupo Intergubernamental de Expertos sobre el Cambio Climático. https://www.ipcc.ch/site/assets/uploads/2018/02/SYR_AR5 FINAL_full_es.pdf

Hayes, M. J., Wilhelmi, O. V. y Knutson, C. L. (2004). Reducing drought risk: bridging theory and practice. Natural Hazards Review, 5(2), 106-113. https://doi.org/10.1061/(ASCE)1527-6988(2004)5:2(106)

Instituto Nacional de Estadísticas (2017). Urbano/Rural: Contexto de los resultados: Diseminación Censo 2017. https://bit.ly/2XSTpPZ

Maturana, J., Bello, M. y Manley, M. (1997). Antecedentes históricos y descripción del fenómeno El Niño, Oscilación del Sur. En Avaria,S., Carrasco, j., Rutllant,J. y Yáñez,E. (eds.). El Niño-La Niña 1997-2000. Sus Efectos en Chile. (pp.13-27). https://bit.ly/3m7o18D

McKee, TB., Doesken, NJ. y Kleist, J. (17-22 de enero de 1993) The relationship of drought frequency and 
duration to time scales. [Presentación en papel]. Conferencia del American Meteorological Society, Anaheim,California. https://bit.ly/3i5eBcr

Muñoz-Schick, M., Pinto, R., Mesa, A. y Moreira-Muñoz, A. (2001). “Oasis de neblina” en los cerros costeros del sur de Iquique, región de Tarapacá, Chile, durante el evento El Niño 1997-1998. Revista chilena de historia natural, 74(2), 389-405. http://dx.doi.org/10.4067/S0716-078X2001000200014

Nasrollahi, M., Khosravi, H., Moghaddamnia, A., Malekian, A., y Shahid, S. (2018). Assessment of drought risk index using drought hazard and vulnerability indices. Arabian Journal of Geosciences, 11(20), 606. https://doi.org/10.1007/s12517-018-3971-y

Organización de las Naciones Unidas para la Ayuda en Casos de Desastre. (1979). Natural Disasters and Vulnerability Analysis: Report of Experts Group Meeting. https://digitallibrary.un.org/record/95986

Organización Meteorológica Mundial. (2006). El Clima y la Degradación de las Tierras (Informe n 989). https://library.wmo.int/doc_num.php?explnum_id=5098

Organización Meteorológica Mundial.(2012). Índice normalizado de precipitación, Guía del Usuario (Informe $\mathrm{n}^{\circ}$ 1090). https://bit.ly/3zEgMcR

Organización de las Naciones Unidas para la alimentación y la agricultura. (2010). Gestión del riesgo de sequía y otros eventos climáticos extremos en Chile. Estudio piloto sobre la Vulnerabilidad y la Gestión Local del Riesgo. https://www.unisdr.org/files/13992_climachl.pdf

Organización de las Naciones Unidas para la alimentación y la agricultura. (2013). Afrontar la escasez de agua. Un marco de acción para la agricultura y la seguridad alimentaria. (Informe sobre temas hídricos n³8). http://www.fao.org/3/i3015s/i3015s.pdf

Rahman, M. R., y Lateh, H. (2016). Meteorological drought in Bangladesh: assessing, analysing and hazard mapping using SPI, GIS and monthly rainfall data. Environmental Earth Sciences, 75(12). https://doi. org/10.1007/s12665-016-5829-5

Rajsekhar, D., Singh, V. P., and Mishra, A. K. (2015). Integrated drought causality, hazard, and vulnerability assessment for future socioeconomic scenarios: An information theory perspective. Journal of Geophysical Research: Atmospheres, 120(13). https://doi.org/10.1002/2014JD022670

Rojas, O. y Martínez, C. (2011). Riesgos naturales: evolución y modelos conceptuales. Revista Universitaria de Geografía, 20(1),83-116. https://bit.ly/2XHHKTu

Shahid, S., y Behrawan, H. (2008). Drought risk assessment in the western part of Bangladesh. Natural hazards, 46(3), 391-413. https://doi.org/10.1007/s11069-007-9191-5

Sharafi, L., Zarafshani, K., Keshavarz, M., Azadi, H., y Van Passel, S. (2020). Drought risk assessment: towards drought early warning system and sustainable environment in western Iran. Ecological Indicators, 114. doi: $\underline{10.1016 / j . e c o l i n d .2020 .106276}$

Tigkas, D., Vangelis, H. y Tsakiris, G. (2015). DrinC: a software for drought analysis based on drought indices. Earth Science Informatics, 8(3),697-709. https://doi.org/10.1007/s12145-014-0178-y

Valiente, Ó. M. (2001). Sequía: definiciones, tipologías y métodos de cuantificación. Investigaciones geográficas, (26), 59-80. https://doi.org/10.14198/INGEO2001.26.06

Van Loon, A. F., Stahl, K., Di Baldassarre, G., Clark, J., Rangecroft, S., Wanders, N., Gleeson, T., Van Dijk, A. I.J.M., Tallaksen, L.M., Hannaford, J., Uijlenhoet, R., Teuling, A.J., Hannah, D.M., Sheffield, J., Svoboda, M., Verbeiren, B., Wagener, T., y Van Lanen, H. A. J.(2016). Drought in a human-modified world: reframing drought definitions, understanding, and analysis approaches. Hydrol. Earth Syst. Sci., 20(9), 3631-3650. https://doi.org/10.5194/hess-20-3631-2016

Vargas, J. y Paneque, P. (2017). Methodology for the analysis of causes of drought vulnerability on the River Basin scale. Natural Hazards, 89(2), 609-621. https://doi.org/10.1007/s11069-017-2982-4

Wilhite, D. A. y Glantz, M.H.(1985). Understanding: the drought phenomenon: the role of definitions. Water international, 10(3), 111-120. https://digitalcommons.unl.edu/droughtfacpub/20/

Zhao, J., Zhang, Q., Zhu, X., Shen, Z., y Yu, H. (2020). Drought risk assessment in China: evaluation framework and influencing factors. Geography and Sustainability, 1(3), 220-22. https://doi.org/10.1016/j. geosus.2020.06.005 